\title{
Student Participation in OSS Projects
}

\author{
Gregory W. Hislop $^{1}$, Heidi J.C. Ellis ${ }^{2}$, Greg DeKoenigsberg ${ }^{3}$, and Darius Jazayeri ${ }^{4}$ \\ ${ }^{1}$ Drexel University \\ hislop@drexel.edu \\ ${ }^{2}$ Western New England College \\ hellis@wnec.edu \\ ${ }^{3}$ Red Hat Inc. \\ gdk@redhat.com \\ ${ }^{4}$ OpenMRS \\ djazayeri@pih.org
}

\begin{abstract}
Open Source Software (OSS) is undergoing extraordinary growth. This rapid growth requires an increasing number of software developers working in a variety of areas. Computing education needs to provide students with professional experience, preferably within the context of a large, distributed software project. Educating students within OSS projects provides a solution to both the need for both developers to work on OSS projects as well as the need to provide computing students with professional experience. This panel will discuss the issues involved with educating students using OSS.
\end{abstract}

\section{Description}

Student participation in Open Source Software has the potential to offer significant benefit both to OSS communities and to educators. For OSS, students can make meaningful contributions, and education that includes OSS experience will help to insure that the number of developers with OSS skills continues to grow. From the education perspective, OSS participation can provide students with exposure to large, real-world projects and help students to understand how to handle the complexity of large, long-lived projects, how to behave in a professional environment, how to communicate effectively in a distributed development environment, and much more.

However, there are a variety of roadblocks to involving students in OSS projects. Instructors perceive high learning curves for projects and development environments, difficulties in obtaining entree into OSS projects, and problems in fitting development within an academic schedule. Students may be concerned with the complexity of the project and being viewed negatively by the OSS community for their lack of experience. OSS participants may be concerned about student inexperience, and the limits of academic term schedules.

This panel will discuss the impact of the growth in OSS on computing education. Questions to be addressed include:

- What is the value of student participation in OSS projects?

- What does it take to involve students in OSS projects including on-ramp issues, student-friendly projects and more? 
- What are the variety of ways that students can participate in an OSS project? Student involvement includes both software and services and can range from coding to documentation to providing support for OSS applications.

- What are some examples of successful efforts within courses?

- What are some existing OSS efforts to involve students?

This panel hopes to encourage active discussion of the issues related to educating students with respect to and in the environment of OSS.

\section{Panelists and Perspectives}

Greg Hislop (panel moderator), is an Associate Professor in the College of Information Science and Technology, Drexel University. He is co-PI on the NSF project "SoftHum: Student Participation in the Community of Open Source Software for Humanity," which is investigating the development of course materials to support student open source participation within the classroom (xcitegroup.org/softhum). He is PI on the HumIT project which is developing ways to have students provide infrastructure support for humanitarian OSS projects (xcitegroup.org/humit). Greg will speak from the perspective of curriculum development for incorporating students in OSS.

Heidi Ellis is Associate Professor and Chair of Department of Computer Science and Information Technology, Western New England College. She is PI on the NSF SoftHum project. She has been involved with the Humanitarian Free and Open Source Software (HFOSS) project (hfoss.org). Heidi will speak from the perspective of instructional delivery and course materials for incorporating students in OSS.

Greg DeKoenigsberg is a Senior Community Architect for Red Hat. He is a former chairman of the Fedora Project, an open source software development community with over 10,000 volunteer contributors. He serves on the advisory boards of several open source advocacy organizations, writes about open source issues, and speaks at open source events worldwide. He has been with Red Hat Since 2001. Greg will discuss his experiences with Red Hat in building collaborative communities that support student involvement in OSS.

Darius Jazayeri is the Lead Software Designer for OpenMRS, an OSS electronic medical record system built by a collaborative that includes the Regenstrief Institute, Inc. and Partners In Health. He has over eight years experience developing open source medical records in developing countries. Darius recently won the 2009 Pizzigati Prize for Public Interest Computing from the Tides Foundation. Darius will discuss his experiences with project management while mentoring students involved in OpenMRS projects. 